\title{
CLIFF DWELLING SPARROW HAWKS IN SOUTHERN SASK.
}

by Richard W. Fyfe, Saskatchewan Museum of Natural History.

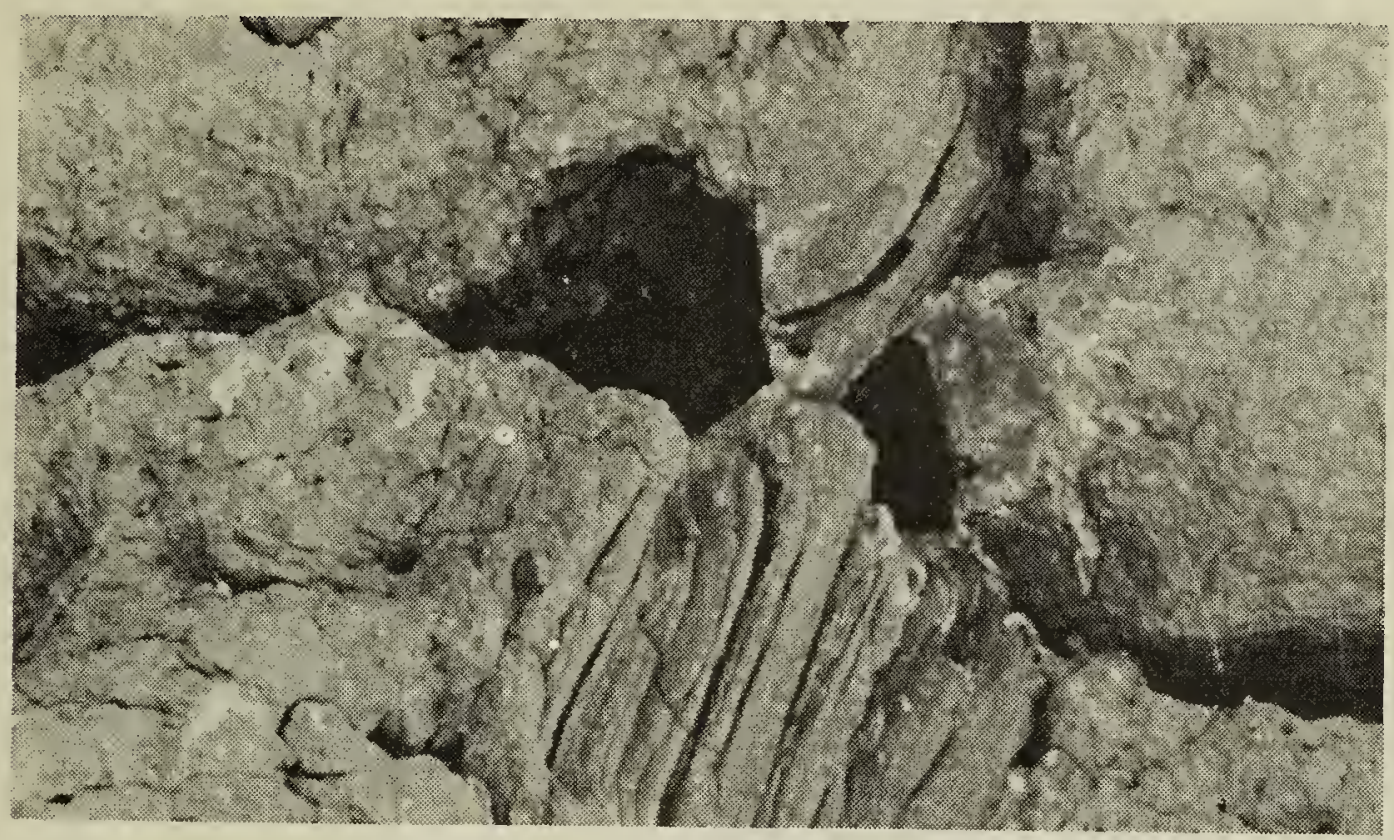

Natural cliff cavity used by Sparrow Hawk Photo by $R$. W. Fyfe

The first records for cliff nesting Sparrow Hawks (Falco spaverious) in Saskatchewan were those made in the Big Mudidy Valley by Dr. Peter Gregg, other members of the Saskatchewan Falconry Asisociation, and myself during May and July of this year. Although Sparnow Hawks usually nest in tree cavities, they have been recorded nesting in cliffs in other regions of North America (Bent, 1938, Life Histories of North American Birds of Prey; Pough,

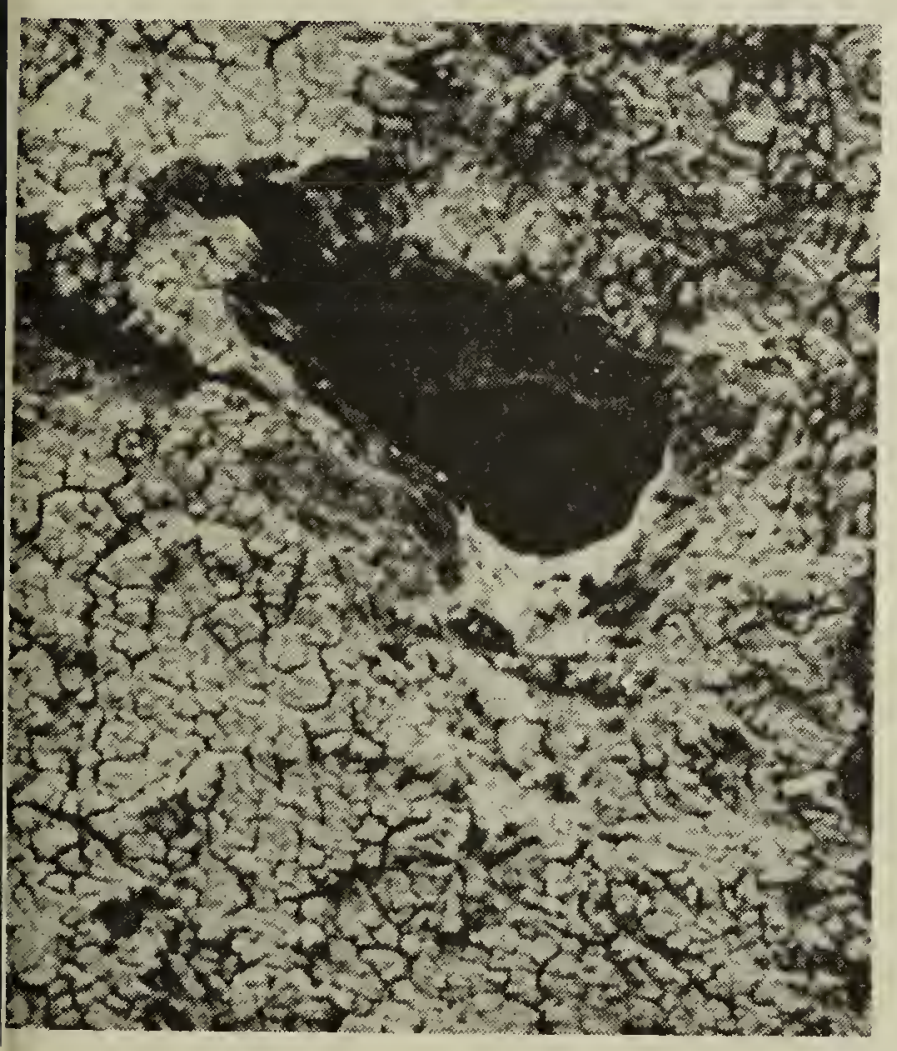

Artificial cliff cavity used by Sparrow Hawk. Photo by R. W. Fyfe
1953, Audubon Guides).

On May 24, 1958, Dr. Gregg and myself located two nests in the Big Muddy Valley. On return visits, July 1 and July 12, seven additional nests were found and recorded. All were located in holes in the valley cliffs in either naturally formed cavities or cavities apparently made by flickers in previous years. The nests were situaited 15 to 50 feet above the valley floor and were easily located by the white staining at the entrances of the cavities. Eight of these nests were examined and were found to contain three to five young birds.

I feel it is safe to assume that Sparrow Hawks have utilized these unusual nest sites due to the absence of tree cavities in an area meeting other requirements of the birds.

\section{SUMMER RECORD OF THE GREAT GRAY OWL}

At 3.30 p.m. on June 13, 1958, Jim Rooke and I had an excellent look at a Great Gray Owl. The bird was on a fence post in an opening adjacent to heavy poplar timber, five miles northeast of Peesane, Saskatchewan. The owl flew into the bush and I was able to find and flush it a second time. It was a dark phase, almost sooty, Great Gray Owi. We had a good view of the round head from about thirty yards. - Elwin Baines, Tisdale. 